\title{
Dossiê:
}

\section{Escola de Praga}

\section{Dossier:}

Prague School

Autor: Valteir Vaz

Fundação Santo André, Santo André, São Paulo, Brasil

Edição: RUS Vol. 12. № 19

Publicação: Agosto de 2021 


\section{Dossiê:}

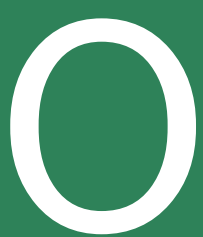

Círculo de Praga, constituinte do que hoje chamamos de Escola de Praga (ou estruturalismo tcheco), corresponde a um movimento que congregou intelectuais de diferentes áreas e nacionalidades na capital tcheca, entre 1929 e 1945. Embora os primeiros estudos desenvolvidos no âmbito do movimento se concentrassem em questões linguísticas, muitos outros campos do conhecimento também foram gradativamente entrando no rol de interesses de seus participantes, com destaque para a estética, folclore, teoria literária, sociologia etc.

Suas ligações com o Formalismo Russo são evidentes, bastando para tanto lembrar o nome de Roman Jakobson, que efetivamente participou dos dois movimentos, trazendo da Rússia um modelo operatório dos fenômenos linguísticos e literários bastante novo na Europa Central. E não se pode, também, deixar de mencionar que os integrantes da Escola desenvolveram uma agenda bastante particular, rente a tradições locais. O fato é que o movimento representou, para dizer o mínimo, um novo paradigma de conhecimento nas humanidades e nas ciências sociais, desempenhando, assim, um papel alternativo ao pensamento positivista de então. As contribuições originais de Vilém Mathesius, Roman Jakobson, Bohuslav Ha- 
vránek, Bohumil Trnka, Jan Rypka, Jan Mukařovský, Felix Vodička, Jindřich Honzl, Oskar Fischer, Nikolai Trubetskói, Peter Bogatyrióv, Serguei Kartsévski, reverberam em movimentos como o Estruturalismo (francês), a Estética da Recepção, a Semiótica da Cultura etc.

É possível traçar um percurso - ainda que tímido - da Escola de Praga no Brasil. Em 1978, Dionísio de Toledo, ex-professor da Universidade Federal do Rio Grande do Sul, em seu exílio francês em decorrência das perseguições da ditadura militar, reuniu e traduziu para o português, com um grupo de tradutores, a mais densa e completa coletânea de ensaios dos melhores representantes da Escola já publicada em solo nacional: Círculo Linguístico de Praga: Estruturalismo e semiologia. A editora que o publicou foi a Globo de Porto Alegre, a mesma que em 1971 havia publicado a primeira coletânea de ensaios dos Formalistas Russos no Brasil, inspirada em Theorie de la litterature. Textes de formalistes russes (1965), com organização e tradução de T. Todorov.

Também de 1978 é o livro Círculo Linguístico de Praga, que Jacó Guinsburg traduziu para a coleção Elos, da Editora Perspectiva. Trata-se de um conjunto de ensaios curtos e na sua maioria de autoria de Jan Mukařovský, cujo foco recai nas questões concernentes à estética.

Ainda com mesmo título e no mesmo ano que os anteriores, é publicado, numa parceria entre as editoras Cultrix e Edusp, - Círculo Linguístico de Praga da linguista francesa Jacqueline Fontaine, traduzido por João Pedro Mendes. O livro se ocupa em verificar as reverberações das ideias de Ferdinand de Saussure entre os integrantes do Círculo e aborda as principais noções que Trubetskói e Jakobson desenvolveram no âmbito da fonologia.

Em 1991, sai pela editora Nova Fronteira a tradução de De Praga a Paris: uma crítica do estruturalismo e do pensamento pós-estruturalista, de José Guilherme Merquior, publicado originalmente em inglês em 1985. De um total de 294 páginas, Merquior dedica dez ao Círculo de Praga ("A Encruzilhada de Praga: entre o formalismo e a sócio-semiótica"), e dessas, a 
maior parte está centrada na figura de Roman Jakobson e nas influências do Formalismo Russo sobre o movimento. De fato, a medir pelo título, há pouca informação sobre o Círculo de Praga, mas, como o próprio autor nos antecipa no prefácio: "a verdadeira localização da história [contada no livro] é o meio da houte culture da Paris moderna". Trata-se de um estudo de fôlego e que movimenta uma gama de fontes e saberes, hoje sob ataque feroz da crítica especializada (Emil Wolek, Lubomír Doležel, Richard Bradford).

Um trabalho profícuo é $A$ identidade e a diferença: Raízes históricas das teorias estruturais da narrativa, do professor Edward Lopes, publicado pelas editoras Edusp e Imprensa Oficial em 1997. A seção dedicada ao Círculo Linguístico de Praga é o trabalho mais exaustivo já escrito sobre o movimento entre nós.

Este dossiê buscou reunir artigos que possibilitassem ao leitor uma perspectiva ampla sobre o movimento, não se concentrando somente em abordagens cuja tônica fosse a linguística, a mais conhecida faceta da Escola. Nesse sentido, o leitor encontrará neste número especial da RUS trabalhos sobre a vida intelectual na cidade de Praga de então, sobre tradições acadêmicas locais que influenciaram seus representantes, sobre a vida turbulenta de Roman Jakobson, acusado tantas vezes de espionagem soviética, sobre as dificuldades de se publicar uma coletânea de obras de Mukařovský na Rússia soviética, sobre o que hoje ainda resta da escola de Praga entre outras tantas abordagens.

Gostaria ainda de render meus agradecimentos aos colaboradores desta edição, ao corpo editorial da RUS e aos diversos pareceristas. Agradecimento especial ao professor Peter Steiner que me encorajou a organizar o volume e me colocou em contato com estudiosos do movimento do mundo todo.

Passemos à leitura.

Valteir Vaz 